University of Nebraska - Lincoln

DigitalCommons@University of Nebraska - Lincoln

\title{
Salsuginus yutanensis n. sp. (Monogenea: Ancyrocephalidae) from Fundulus sciadicus in Clear Creek of Eastern Nebraska
}

\author{
Michael T. Ferdig \\ University of Notre Dame, Michael.T.Ferdig.1@nd.edu \\ Mary Ann McDowell \\ University of Notre Dame, mcdowell.11@nd.edu \\ John J. Janovy Jr. \\ University of Nebraska - Lincoln, jjanovy1@unl.edu
}

Follow this and additional works at: https://digitalcommons.unl.edu/bioscijanovy

Part of the Parasitology Commons

Ferdig, Michael T.; McDowell, Mary Ann; and Janovy, John J. Jr., "Salsuginus yutanensis n. sp.

(Monogenea: Ancyrocephalidae) from Fundulus sciadicus in Clear Creek of Eastern Nebraska" (1991).

John Janovy Publications. 43.

https://digitalcommons.unl.edu/bioscijanovy/43

This Article is brought to you for free and open access by the Papers in the Biological Sciences at DigitalCommons@University of Nebraska - Lincoln. It has been accepted for inclusion in John Janovy Publications by an authorized administrator of DigitalCommons@University of Nebraska - Lincoln. 


\title{
SALSUGINUS YUTANENSIS N. SP. (MONOGENEA: ANCYROCEPHALIDAE) FROM FUNDULUS SCIADICUS IN CLEAR CREEK OF EASTERN NEBRASKA
}

\author{
M. T. Ferdig, Mary Ann McDowell, and J. Janovy, Jr. \\ School of Biological Sciences, University of Nebraska-Lincoln, Lincoln, Nebraska 68588-0118
}

\begin{abstract}
Salsuginus yutanensis n. sp. (Monogenea: Ancyrocephalidae) is described from the gills of the plains topminnow, Fundulus sciadicus Cope, from Clear Creek in eastern Nebraska. Salsuginus yutanensis is distinguished from previously described species by having a shorter accessory piece and different hamulus proportions, especially in the relative lengths of deep and superficial roots. In addition, the angles between deep and superficial roots distinguish $S$. yutanensis from several congeners.
\end{abstract}

Previous studies have concerned the ecology of parasites of Fundulus zebrinus in Nebraska (Knight et al., 1980; Adams, 1986; Janovy and Hardin, 1988; Janovy et al., 1990). Ecological work has now been extended, in part, to another fish species, Fundulus sciadicus Cope, the plains topminnow, which occurs in disjunct populations occupying habitats quite different from those of $F$. zebrinus. An ancyrocephalid gill monogenean on $F$. sciadicus evidently is not the same species as that on F. zebrinus, and consequently it is described in the present paper.

\section{MATERIALS AND METHODS}

Fish were collected from backwater of 3 clear, springfed streams in Nebraska: Clear Creek, $5 \mathrm{~km}$ south and $3.3 \mathrm{~km}$ east of Yutan, Saunders County, Nebraska; Bull Ditch, $1.9 \mathrm{~km}$ north, and Cedar Creek, $3.2 \mathrm{~km}$ north, of Paxton, Keith County, Nebraska. Sixty fish ranging from 38 to $63 \mathrm{~mm}$ long and collected in July 1988 were examined. Gills were excised and placed in $1 \%$ chloral hydrate for up to $1 \mathrm{hr}$. Worms were removed with insect pin probes, fixed in alcohol-formalin-acetic acid, washed in $70 \%$ ethanol, and either cleared, and temporarily mounted in glycerin; cleared in glycerin and mounted in glycerin jelly; stained in acetocarmine or hemotoxylin, dehydrated, cleared in xylene, and mounted in Canada balsam; or dehydrated, cleared in xylene, and mounted in Canada balsam. Ninety-five specimens were studied, 45 of which were mounted temporarily in glycerin for measurement of sclerotized parts.

Measurements were taken according to the protocols of Murith and Beverley-Burton (1985). To assess morphological differences between dorsal and ventral hamuli of the same species and hamuli of various species, ratios, consisting of $d / c$ and $x / y$ (Janovy et al., 1989), and angle between deep and superficial roots were determined. Measurements are given in micrometers as means with ranges, standard deviation, and number of

Received 31 May 1990; revised 4 September 1990; accepted 4 September 1990. measurements in parentheses. Angles between superficial and deep roots of previously described species were determined from published figures. Drawings in Figures 1-7 were made with the aid of a camera lucida. A series of 1-way ANOVAs was performed to assess variation of measurements, ratios, and angles within and among collecting sites.

\section{DESCRIPTION Salsuginus yutanensis \\ (Figs. 1-7)}

Diagnosis: Ancyrocephalidae with characters of the genus Salsuginus as defined by Murith and BeverleyBurton (1985). Body 309 (173-418, 54.9, 45) long by $84(47-153,23.3,45)$ in maximum width (midbody); haptor $37(25-52,6.6,45)$ long by $54(30-75,11.1,45)$ wide; pharynx $30(23-37,4.1,45)$ in transverse diameter. Both hamuli with long, thin curved blade and superficial root larger than deep root (Figs. 2, 3). Dorsal (Fig. 2) and ventral (Fig. 3) hamuli similar in shape, except that angle between deep and superficial root smaller in the dorsal hamuli than in the ventral. Standard hamular measurements (see Murith and BeverleyBurton, 1985): Dorsal $a=18(16-20,1.3,45), b=17$ $(15-19,1.0,45), c=3(2-5,0.6,45), d=8(6-9,0.6$, $45), e=6(5-7,0.6,45), x=10(8-11,0.7,45), y=9$ $(8-10,0.85,45), d / c$ ratio mean (standard deviation, n) $=2.3(0.4,45), x / y$ ratio $=1.1(0.1,45)$; ventral $a$ $=22(20-24,1.0,45), b=21(19-23,1.0,45), c=3$ $(2-4,0.4,45), d(7-11,0.9,45), e=7(5-8,0.5,45)$, $x=12(11-13,0.6,45), y=11(9-12,0.8,45), d / c$ ratio $=3.3(0.5,45), x / y$ ratio $=1.1(0.01,45)$. Dorsal bar $22(20-27,2.0,45)$ long by $3(2-4,0.3,45)$ wide. Ventral bar $25(22-30,2.2,45)$ long by $4(3-5,0.5,45)$ wide. Larval hooks $12(11-13,0.3,45)$. Penis tubular, $17(15-19,1.2,43)$ long (straight line base to tip), distal aperture $2(1-3,0.1,43)$ wide. Accessory piece 13 (12$14,1.1,43)$ long, terminal end with pointed branches distally and 2 small lobes proximally (Fig. 6).

\section{Taxonomic summary}

Type host: Fundulus sciadicus Cope, 1885, the plains topminnow.

Type locality: U.S.A., Nebraska, Saunders County, Clear Creek, $5 \mathrm{~km}$ south and $3.3 \mathrm{~km}$ east of Yutan.

Specimens deposited: One holotype (USNM No. 

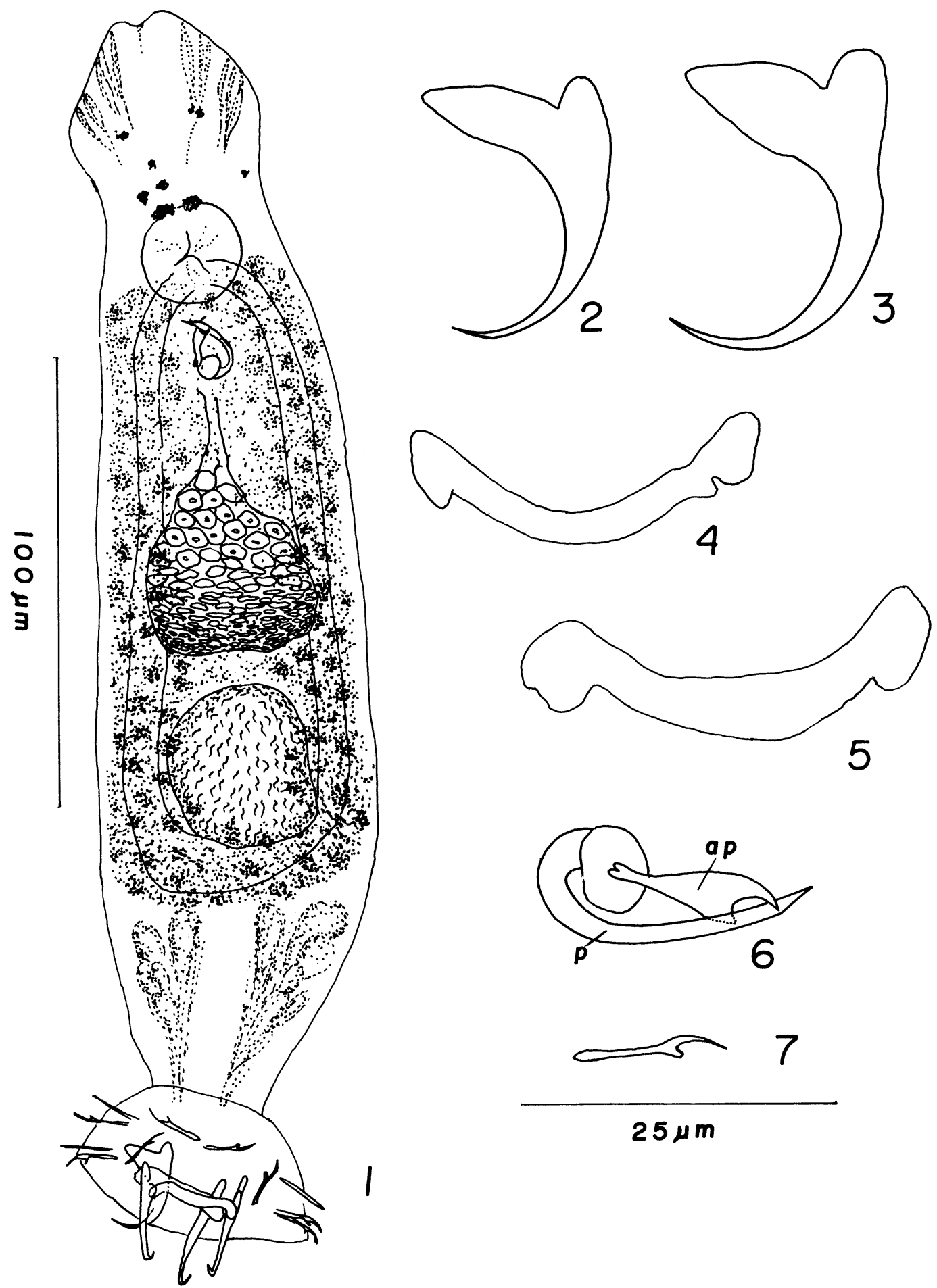

$25 \mu \mathrm{m}$

Figures 1-7. Salsuginus yutanensis n. sp. 1. Whole worm, ventral view. 2. Dorsal hamulus. 3. Ventral hamulus. 4. Dorsal bar. 5. Ventral bar. 6. Male copulatory structures. 7. Larval hook. ap, accessory piece; p, penis. 
$81115)$ and 24 paratypes (USNM No. 81116) in the United States National Museum Helminthological Collection, Beltsville, Maryland. Twenty-five paratypes (UNSM No. 33103) in the H. W. Manter Laboratory, University of Nebraska State Museum, Lincoln, Nebraska.

Etymology: The name yutanensis refers to the village, Yutan, near the type locality.

\section{Remarks}

Salsuginus yutanensis is similar to Salsuginus thalkeni Janovy, Ruhnke, and Wheeler, 1989, Salsuginus angularis (Mueller, 1934) Beverley-Burton, 1984, Salsuginus spirae (Williams, 1980) Murith and BeverleyBurton, 1985, Salsuginus bermudae Rand and Wiles, 1987, Salsuginus bahamianus (Hanek and Fernando, 1972) Murith and Beverley-Burton, 1985, Salsuginus seculus (Mizelle and Arcadi, 1945) Murith and Beverley-Burton, 1985, and Salsuginus heterocliti Murith and Beverley-Burton, 1985, in having dorsal hamuli smaller than ventral ones, and different from Salsuginus umbraensis (Mizelle, 1938) Murith and BeverleyBurton, 1985, and Salsuginus fundulus (Mizelle, 1940) Beverley-Burton, 1984, in which dorsal and ventral hamuli are approximately the same size. Salsuginus yutanensis differs from $S$. angularis and $S$. heterocliti in having proportionally shorter superficial roots in dorsal and ventral hamuli $(d / c=2.3$ and 3.3 vs. 3.3 and 4.3 and 3.3 and 4.0 , respectively), and from $S$. seculus in having proportionally shorter superficial roots in the dorsal hamuli $(d / c=3.3$ vs. 5.0$)$.

The new species differs from $S$. seculus, $S$. spirae, and $S$. bahamianus in having dorsal hamuli that are proportionally wider (dorsal $x / y=1.1$ vs. $0.7,0.7$, and 0.8 , respectively), and it differs from $S$. bermudae in having wider ventral hamuli than dorsal hamuli. Salsuginus yutanensis hamuli are dimorphic in that their sizes are significantly different and their $d / c$ ratio is larger for the ventral hamuli ( 3.3 vs. 2.3$)$ than for dorsal.

The angles formed by the deep and superficial roots consistently are greater in the ventral hamuli of $S$. $y u$ tanensis than in the dorsal hamuli, although ranges overlap $\left(62-83^{\circ}\right.$ and $\left.53-73^{\circ}\right)$. This feature is in contrast to $S$. thalkeni and $S$. fundulus, in which the dorsal $d / c$ angle is greater, and to $S$. spirae in which the ventral $d / c$ angle is very much greater than the dorsal.

The accessory piece of the male copulatory apparatus has less pronounced proximal lobes than are observed for most of the other species. The accessory piece is also considerably shorter in this species than in all others except $S$. fundulus and perhaps $S$. seculus. The ranges of accessory piece measurements from all sites did not overlap those of $S$. thalkeni. As is common for this genus, the structure of the dorsal and ventral bars is quite variable in the extent of curvature and depth and position of grooves.

Analysis of variance revealed that there is considerable site-related variation in many of the morphometric characters. For example, hamulus length ( $a$ and b) varied significantly among 3 collection sites distributed over a $500-\mathrm{km}$ distance, although all ranges overlapped broadly. However, shape of dorsal and ventral hamuli, as determined by ratios and root angles, and the relationship between dorsal and ventral hamuli generally were more constant despite variations in size.

\section{DISCUSSION}

Salsuginus systematics has relied heavily on sizes of hamuli and shapes of the accessory piece (Mizelle and Arcadi, 1945; Murith and BeverleyBurton, 1985; Rand and Wiles, 1987). In response to concerns of Rand and Wiles (1987), Janovy et al. (1989) suggested that ratios, angles, and meta-measurements be used to better assess morphological similarities and differences among the Salsuginus species. Rand and Wiles (1987) determined that 2 morphotypes of $S$. bermudae collected from Fundulus bermudae in 2 lakes could be distinguished using differences in accessory piece structure. They suggested that the different accessory pieces reflected environmental differences between lakes rather than biological speciation of the parasite groups. Worms collected from the gills of $F$. sciadicus from 3 sites in Nebraska in July 1988 showed extensive morphometric variation. However, use of other criteria such as ratios indicates that although sizes of sclerotized parts vary from site to site, proportions within and between dorsal and ventral hamuli are relatively constant. We suggest these variations are attributable to the influence of environmental conditions on development.

In general, the habitats of the 2 Nebraska Fundulus species do not overlap. Fundulus zebrinus occurs through the Platte River main stream, whereas $F$. sciadicus occurs in relatively isolated populations almost wholly restricted to ditches and small oxbows of spring-fed streams. Furthermore, the 2 species differ in feeding habits, $F$. zebrinus being a bottom feeder and $F$. sciadicus a top feeder. In addition, there is evidence that the 2 host species are not particularly closely related, and in fact, some authors consider $F$. zebrinus a member of a monotypic genus Plancterus (see Wiley [1986] for analysis of this problem). Thus there is no a priori reason to suspect that the Salsuginus species of the 2 Nebraska species of the genus Fundulus are the same, if Murith and Beverley-Burton (1985) are correct in their conclusions about host specificity in this genus of worms.

\section{ACKNOWLEDGMENTS}

The authors thank Drs. A. Joern and L. Vescio for use of facilities at Cedar Point Biological Station.

\section{LITERATURE CITED}

ADAms, A. 1986. The parasite community on the gills of Fundulus kansae (Garman) from the South Platte 
River, Nebraska (USA). Acta Parasitologica Polonica 31: 47-54.

JANOVy, J., JR., M. T. Ferdig, AND M. A. MCDowell. 1990. A model of dynamic behavior of a parasite species assemblage. Journal of Theoretical Biology 142: 517-529.

- AND E. L. HARDIN. 1988. Diversity of the parasite assemblage of Fundulus zebrinus in the Platte River of Nebraska. Journal of Parasitology 74: 207-213.

, T. R. Ruhnke, AND T. A. Wheeler. 1989. Salsuginus thalkeni n. sp. (Monogenea: Ancyrocephalidae) from Fundulus zebrinus of the South Platte River of Nebraska. Journal of Parasitology 75: 344-347.

Knight, S. A., J. Janovy, JR., AND W. L. CURrent. 1980. Myxosoma funduli Kudo 1918 (Protozoa: Myxosporidia) in Fundulus kansae (Pisces: Cyprinodontidae): Annual prevalence and geographic distribution. Journal of Parasitology 66: 806810.

Mizelle, J. D., AND J. A. Arcadi. 1945. Studies on monogenetic trematodes XIII. Urocleidus seculus, a new species of Tetraonchinae from the viviparous top minnow, Gambusia affinis affinis (Baird and Girard). Transactions of the American Microscopical Society 64: 293-296.

Murith, D., AND M. Beverley-Burton. 1985. Salsuginus Beverley-Burton 1984 (Monogenea: Ancyrocephalidae) from Cyprinodontoidei (Atheriniformes) in North America with descriptions of Salsuginus angularis (Mueller, 1934) BeverleyBurton, 1984 from Fundulus diaphanus and Salsuginus heterocliti $n$. sp. from $F$. heteroclitus. Canadian Journal of Zoology 63: 703-714.

RAND, T. G., AND M. Wiles. 1987. Salsuginus bermudae sp. n. (Monogenea: Ancyrocephalidae) from Fundulus bermudae Gunther and Gambusia affinis (Baird and Girard) in Bermuda. Canadian Journal of Zoology 65: 1847-1852.

WiLEY, E. O. 1986. A study of the evolutionary relationships of Fundulus topminnows (Teleostei: Fundulidae). American Zoologist 26: 121-130. 